\title{
Is there really very rapid forgetting from primary memory? The role of expectancy and item importance in short-term recall
}

\author{
THOMAS F. CUNNINGHAM \\ St. Lawrence University, Canton, New York \\ ALICE F. HEALY \\ University of Colorado, Boulder, Colorado \\ ROBERT E. TILL \\ University of North Dakota, Grand Forks, North Dakota \\ DAVID W. FENDRICH \\ Widener University, Chester, Pennsylvania \\ and \\ CHRISTINA Z. DIMITRY \\ St. Lawrence University, Canton, New York
}

\begin{abstract}
In two experiments, subjects recalled one of two letter segments following a digit-filled retention interval. In Experiment 1, recall expectancy was manipulated by using precues that correctly informed or misinformed subjects concerning which letter segment would be tested for recall. In Experiment 2, item importance was varied by precuing one segment as important but requiring that the uncued segment be recalled first. Recall performance was very low under conditions of low expectancy and low segment importance, but the slopes of the retention functions did not demonstrate more rapid forgetting than under standard conditions. The previous observations of very rapid forgetting from primary memory may be a function of an elevated initial recall level in the earlier studies. Our retention functions were compared with predictions of the Estes perturbation model. The findings suggested that when secondary memory processes were reduced, forgetting order information from primary memory occurred at the same rate as that estimated on the basis of previous studies using the standard distractor task.
\end{abstract}

The distractor paradigm developed by Brown (1958) and Peterson and Peterson (1959) has been used to assess short-term memory (i.e., retention over brief time intervals). Findings from this paradigm have revealed a steep retention function, which has been interpreted as

\footnotetext{
Experiment 1 was conducted at the University of Colorado, Boulder, where R.E.T. was on sabbatical leave 1984-1985. The research was supported in part by National Science Foundation Grant BNS80-25020 and Army Research Institute Contract MDA903-90-K-0066 to the In stitute of Cognitive Science at the University of Colorado; by Biomedical Research Support Grant RR07013-16 awarded to the University of Colorado by the Biomedical Research Support Grant Program, Division of Research Resources, National Institutes of Health; by a research contract from the United States Air Force subcontracted from Universal Energy Systems to the Institute of Cognitive Science at the University of Colorado; and by special research funds provided through a Faculty Research Award from St. Lawrence University. We wish to thank Antoinette Gesi for her help in the conduct and data entry of Experiment 1, Bill Marmie for his help in figure preparation and model fitting, and Peggy Intons-Peterson, Paul Muter, Rose Zacks, John Gardiner, and five anonymous reviewers for their thoughtful comments concerning earlier versions of this manuscript. Correspondence should be addressed either to T. F. Cunningham, Department of Psychology, St. Lawrence University, Flint Hall, Canton, NY 13617, or to A. F. Healy, Department of Psychology, University of Colorado, Campus Box 345, Muenzinger Building, Boulder, CO 80309-0345.
}

reflecting the rapid time course of forgetting information from primary memory (i.e., a hypothetical temporary memory system; see, e.g., Waugh \& Norman, 1965). Other important results with the distractor paradigm include the symmetrical bow-shaped serial position functions in the recall of order information, which have been interpreted as reflecting perturbation processes in primary memory (e.g., Lee \& Estes, 1977).

Although it has long been acknowledged that short-term memory tasks may involve aspects of secondary memory (i.e., a hypothetical permanent memory system) as well as primary memory, two independent lines of investigation have recently emphasized the important role of secondary memory in the recall functions obtained with the distractor paradigm. First, work by Muter (1980) and Sebrechts, Marsh, and Seamon (1989) has demonstrated that the retention function in the distractor paradigm is dramatically influenced by whether the subject is led to expect a recall test after a retention interval, although only secondary memory, not primary memory, should be influenced by encoding strategies that are promoted by expectancy. When expectancy is low, the overall rate of forgetting suggested by these experiments is very rapid and 
considerably steeper than that suggested by the original studies (e.g., Murdock, 1961). Second, earlier work by us (Healy, Fendrich, Cunningham, \& Till, 1987) in which extended time delays were used in the distractor paradigm has demonstrated that a secondary-memory component must be added to the primary-memory perturbation processes for an accurate account of forgetting and serial position functions in the recall of order information. Although there was no change in the primary-memory forgetting component, the secondary-memory component was sizable when subjects were led to expect in advance which one of two segments would be tested for recall, but was also necessary when no advance notice was provided. These two lines of investigation indicate that the subjects' expectancy concerning test procedure plays an important role in the retention functions obtained in the distractor paradigm, with recall depressed when expectancy is reduced in both cases. The overall rapid rate of forgetting found in the first line of investigation raises the interesting question of whether the rate of forgetting from primary memory is affected by expectancy. The results of the second line of investigation suggest that there is no change in the rate of forgetting from primary memory when there is a reduction in the contribution of secondary memory processes. However, the reduction of secondary memory. processes was modest in the second line of investigation relative to that attained in the first line of investigation.

In the present study, we continue the second line of investigation, in an attempt to achieve a more powerful reduction of secondary memory processes and to examine the rate of forgetting from primary memory when primary memory processes are isolated as much as possible. In the present two experiments, different experimental manipulations were used to achieve this goal. In the first experiment, we varied the subjects' expectancy for a specific recall test. In contrast, in the second experiment, we held expectancy constant, and varied the importance of the material to be recalled.

\section{Very Rapid Forgetting}

Muter (1980) hypothesized that subjects in the distractor paradigm expect to recall the items after a delay filled with a distractor task such as counting, and, consequently, that they may engage in encoding strategies designed to produce a more durable memory trace. In two experiments, he attempted to remove the influence of secondary memory by reducing subjects' expectancy that the items would be tested after a filled delay. He reduced this expectancy by including a large number of trials that either did not require recall at all (instead, only performance on a counting task) or did require recall but only after an unfilled retention interval. Only a very small minority of the trials (e.g., 1 out of 128 trials in his first experiment) were critical test trials that required recall after a delay filled with the interpolated counting task. In his first experiment, the subjects were not informed that such critical trials would occur, but in his second experiment, to avoid the possible confounding effect of a surprise recall test, the subjects were informed in advance that $2 \%$ of the trials would require recall following a filled retention interval. The data from both experiments indicated that when expectancy of recall was low, overall forgetting of material was several times more rapid than that suggested by previous investigations in which the standard distractor paradigm was used and subjects did expect recall following an interpolated distractor task.

In subsequent research, Sebrechts et al. (1989) compared recall in the Muter and distractor paradigms by using three different types of orienting tasks that were designed to affect the degree of elaborative encoding and that were known to produce different levels of recall performance in tests of long-term retention (see, e.g., Craik \& Lockhart, 1972). Sebrechts et al. found that the effects of manipulating expectancy and orienting task were independent. That is, the predicted differences in recall levels were obtained between the Muter and distractor paradigms; but in both paradigms, the retention function was found to be influenced by the type of orienting task (i.e., by the level of processing), thereby implying that the degree of elaborative encoding is an important determinant of performance even when subjects do not expect to recall the words after a filled delay.

\section{Cuing Order Information}

To examine the effects of cuing on short-term memory for order information, in earlier work we (Cunningham, Healy, \& Williams, 1984; Healy et al., 1987) employed a partial report paradigm similar to that developed by Lee and Estes (1981); for analogous procedures in the study of iconic memory and short-term retention, see also Sperling (1960), Brown (1954), and Anderson (1960). In our partial report procedure, a list of to-be-remembered letters was divided into two segments, only one of which was cued for recall at the time of test. The distractor task occurring during the retention interval consisted of reading aloud rapidly presented digits. The cue designating which segment of letters was to be recalled occurred either only at the end of the sequence of letters and distractor digits (postcue) or both at the end of and prior to the sequence (precue). We found consistently superior recall with the precue relative to that with the postcue. The locus of the precuing advantage was the major question addressed in the study by Healy et al. (1987): Did precuing have its effect by enhancing encoding at the initial presentation of the segment or by facilitating rehearsal during the period between the presentation of the segment and its test? An encoding effect would be attributable to secondary memory, whereas a rehearsal effect would be attributable to primary memory. We used two different approaches to answer this question. First, we compared the original Estes perturbation model for order information (Estes, 1972; Lee \& Estes, 1981) with a modified version of the model (Estes, 1983 ) in their ability to account for performance under precue and postcue conditions over extended retention intervals up to $30 \mathrm{sec}$. The original model included only primary-memory rehearsal processes, whereas the modi- 
fied model added a secondary-memory encoding component. The results revealed superior fits for the modified model in both the precue and postcue conditions, thus implicating secondary memory processes in this task. Furthermore, encoding rather than rehearsal processes were implicated as the basis for the advantage due to precuing, because the best fits to both precue and postcue conditions were obtained by changing the value of only the secondary-memory encoding component, not the primarymemory rehearsal component.

In our second approach to this question, we (Healy et al., 1987) devised a more direct empirical test of whether rehearsal processes could be responsible for the precuing advantage. Specifically, we compared the postcue and precue conditions with a new intermediate cue condition, in which the recall cue occurred both at the end of the sequence of to-be-remembered letters and distractor digits and between the presentation of the letters and digits. Because the intermediate cue was presented after the to-beremembered letters, it could only influence rehearsal, not encoding, processes. As before, we found superior performance for the precue relative to the postcue, but we found no facilitating effect of the intermediate cue. The absence of an advantage for the intermediate cue implied that there was no enhanced rehearsal of the cued segment during the digit-filled retention interval. Thus, the combined results of our two approaches indicated that the locus of the precuing advantage is in the initial encoding of the to-be-remembered material.

The enhanced performance in the precue condition raises the question of the fate of the uncued segment. If one assumes that the precued segment receives more extensive encoding, the uncued segment may receive less extensive coding relative to that given to segments in the postcue condition. Hence, examining performance on the uncued segment in the precue condition would provide an excellent opportunity in which to reduce the operation of secondary-memory encoding processes and thereby improve our ability to assess the operation of primary memory processes. We would, thus, be in an optimal position to examine the rate of forgetting from primary memory. In the two experiments presented here, we used different methods to achieve this goal.

\section{EXPERIMENT 1}

The purpose of Experiment 1 was to isolate and study the operation of primary memory processes in the recall of order information. We employed the partial report procedure with the digit-reading distractor task used in our earlier research (Cunningham et al., 1984; Healy et al., 1987) and presented two four-letter segments on each trial. As baselines we included both the precue and the postcue conditions. It is assumed that these conditions elicit different degrees of elaborative encoding of the cued segment. The precue condition should lead to a stronger degree of encoding, because before the segments are presented the subject is told which segment will be tested. In contrast, the postcue condition should result in a weaker degree of encoding because the subject is not told which of the two segments will be tested until the end of the filled retention interval. To reduce further the degree of encoding, and thus create a better test of primary memory processes, we introduced a new condition in which the subject was misinformed about which segment would be tested. Following Muter (1980) and investigators of attentional processes (see, e.g., the priming study by Neely, 1977), we varied the subjects' expectancy by including a small number of critical trials embedded within a majority of filler trials. Whereas $75 \%$ of the trials in this condition were standard precue trials, the remaining $25 \%$ were critical trials in which the precue and postcue were switched so that they did not correspond. Recall expectancy for the segment not signaled by the precue on a critical trial should be low, because on most of the trials there was a match between the precue and the postcue. Note that whereas Muter varied the subjects' expectancy concerning whether recall would be required after a filled interval, we varied the subjects' expectancy concerning whether a particular segment would be cued for recall. Because of the low recall expectancy, performance should be depressed on the critical (switch) trials of the new condition relative to that on all other trials. It will be of interest to determine whether the rate of forgetting across the retention interval is also greatest on the critical trials, as suggested by the findings of Muter.

As in Experiment 2 of the study by Healy et al. (1987), we used two rates of item presentation in the present experiment. In the earlier study, presenting the stimuli at the slow rate of presentation improved retention relative to the fast rate, especially in the precue condition, suggesting that the slow rate was particularly conducive to the improved secondary-memory encoding processes engendered by the precue. If indeed the slow rate of presentation aids encoding processes, then in the present experiment we should find improved performance with the slow presentation rate in the new condition only on the standard precue trials, not on the critical trials in which the precue and postcue are switched, because the degree of encoding should be reduced in that case.

\section{Method}

The method of this experiment was based on that of the earlier experiments by Healy et al. (1987).

Subjects. Forty-eight male and female undergraduate students attending introductory psychology classes at the University of Colorado, Boulder, participated as subjects in order to fulfill a course requirement. There were 8 subjects in each of two conditions, precue and postcue, and 32 subjects in a third condition, $75 \%$ precue. The assignment of an unequal number of subjects across conditions was done purposely to equate the number of critical observations in the $75 \%$ precue condition with the total number of observations in the standard precue and postcue conditions. Within each condition, there was an equal number of subjects in each of two rate orders: fast first and slow first. The assignment of subjects to conditions and rate orders was determined according to a fixed rotation that was based on the time of arrival for testing.

Apparatus and Stimulus materials. A Visual 200 CRT terminal, controlled by a PDP-11/03 computer, was used for the visual display of the stimuli. The CRT screen was located on a table so 
that when a subject was seated, the center of the screen was approximately at eye level. The alphanumeric characters were presented one at a time in a single location at the approximate center of the screen. The characters were $4 \times 2 \mathrm{~mm}$, and all were uppercase. Each trial began with the display of a single hyphen for $1 \mathrm{sec}$. The computer was programmed to display each of the remaining characters (including the recall cues) for $500 \mathrm{msec}$ (fast rate) or $1,000 \mathrm{msec}$ (slow rate), with a negligible interstimulus time interval between characters. Note that the exposure rate for the to-beremembered letters is equivalent to that for the distractor digits. As in earlier studies (Healy, Cunningham, Gesi, Till, \& Bourne, 1991; Healy et al., 1987), this confounding was done purposely so that the tempo of stimulus presentation would be constant and not a source of disruption to the subjects. The time interval between the presentation of stimuli on two successive trials was $16 \mathrm{sec}$, with a buzzer prompt after every $8 \mathrm{sec}$.

Each experimental trial included the presentation of a pair of fourletter segments followed by a digit-filled retention interval. Two retention intervals were used: 4 and 12 digits. An exclamation point marked the boundary between the first and second four-letter segment in each pair and that between the letters and the digits, and a recall cue (".", or "."') at the end of the digit sequence indicated to the subject to write down either the first or the second four-letter segment. At the start of each letter sequence in the postcue condition was an exclamation point; at the start of each letter sequence in the precue and $75 \%$ precue conditions was one of the two recall cue symbols. On all the trials in the precue condition and on $75 \%$ of the trials in the $75 \%$ precue condition (no-switch trials), the symbol at the start of the sequence of letters and digits matched the recall cue at the end of the sequence, whereas on the remaining $25 \%$ of the trials in the $75 \%$ precue condition (switch trials), the initial and final recall cue symbols were different. A sample switch trial with mismatching symbols in the $75 \%$ precue condition consisted of the following characters: -.HKBF!RMLQ!313731518413:

Design. A sequence of 96 experimental trials included four 24 trial blocks. Each of the two retention intervals (4 and 12 digits) occurred 12 times per block, 6 times with each segment position cued for recall (first or second). In every block of the $75 \%$ precue condition, 3 of the 12 trials at each retention interval were switch trials and the remaining 9 trials were no-switch trials. In addition, in both the first two blocks and the last two blocks of the $75 \%$ precue condition, 3 of the 12 trials at each retention interval-segment position combination (e.g., Retention Interval 4-Segment 1) were switch trials and the remaining 9 trials were no-switch trials.

Because the retention of order information was the concern of this study, the letters used in each segment remained constant. For the experimental trials, the first four-letter segment in each pair always consisted of the letters BFHK (consonants from the early part of the alphabet), and the second segment always consisted of the letters LMQR (consonants from the latter part of the alphabet). These letters were chosen in part to avoid acoustically confusable letter pairs. The 24 permutations of the four letters in the first segment were randomly paired with the 24 permutations of the four letters in the second segment. Each of the 24 pairs of four-letter permutations occurred four times always at the same retention in terval, once per block, once with each segment position cued in both the first two and last two blocks, and for the $75 \%$ precue condition once in a switch trial and three times in a no-switch trial. The order of the 24 trials within each block was pseudorandom. The position of each block was constant across subjects. The first two blocks were assigned to one rate (fast or slow), and the last two blocks to the other rate. Rate order (fast first or slow first) was counterbalanced across subjects within each of the three cue conditions (precue, postcue, and $75 \%$ precue).

The interpolated digits displayed on each experimental trial were randomly selected from the digits $1-9$, with the constraint that no digit could occur twice in a row.
Eight practice trials were presented before the experimental trials. Unlike in the experimental trials, the first four-letter segment always consisted of the letters ABCD, and the second, EFGH. None of the practice trials were switch trials. Thus, practice trials in the precue condition were used with experimental trials in both the precue and the $75 \%$ precue conditions, and practice trials in the postcue condition were used with experimental trials in the postcue condition

Procedure. The subjects were tested individually in sessions that lasted 60-65 min. Each subject was instructed to read aloud the name of each letter and digit as it appeared on the display screen, to say "mark" at the appearance of an exclamation point, "first" at the appearance of a period (single dot), and "last" at the appearance of a colon (two dots). The experimenter remained by the subject's side to ensure that the subjects read aloud all characters as they appeared on the display monitor. At the end of a sequence of letters and digits in the postcue condition and at both the beginning and the end of a sequence in the precue and $75 \%$ precue conditions, the recall cue indicated to the subjects which one of the two four-letter segments was to be recalled. The one-dot cue (.) was an indicator for the first segment, and the two-dot cue (:), for the second. On each trial, the subjects were given $16 \mathrm{sec}$ to write down the four letters of the cued segment in their order of appearance on that trial. The subjects entered their responses on small sheets of paper. These sheets included a horizontal array of four squares, one for each letter. The subjects were not allowed to leave a square blank; they were encouraged to guess if necessary. The subjects were told the four letters that constituted the first segment and those that constituted the second segment, and this information was placed on a display card and left in the subjects' view throughout the course of the experimental trials. In the precue condition, the subjects were told that whenever a period or colon occurred at the start of a trial, the same recall cue would occur at the end of a trial. In the $75 \%$ precue condition, the subjects were told that the symbol appearing at the beginning of a trial would predict the symbol appearing at the end "about $75 \%$ of the time." There was a short rest break of at least $1 \mathrm{~min}$ at the end of each block. After the second block, the subjects were told that the subsequent trials would be presented at a different rate (faster or slower), and the eight practice trials were repeated at the new rate before the last two blocks of experimental trials.

\section{Results}

In the analysis of the data, each of the four letters recalled on a given trial was scored separately. A response was considered correct only when the letter recalled at a particular position matched the letter presented at that position. The results were analyzed in terms of an analysis of variance (ANOVA) for unequal $N(N=8$ in the precue condition, $N=8$ in the postcue condition, and $N=$ 32 in the $75 \%$ precue condition), with unweighted means. The dependent variable was the proportion of correct responses. The ANOVA included two between-subjects factors-cue condition (precue, postcue, or $75 \%$ precue) and rate order (fast first or slow first), and it included five within-subjects factors-trial type (switch or no switch), exposure rate (fast or slow), retention interval (4 or 12 digits), position of cued segment (first or second), and serial position within a segment $(1,2,3$, or 4$)$. The factor of trial type was meaningful only for the $75 \%$ precue condition, but the corresponding trials were also used in the precue and postcue conditions for purposes of comparison. Thus, "switch" trials in the precue and postcue 
Table 1

Proportions of Correct Responses in Experiment 1 as a Function of Cue Condition, Rate Order, Trial Type, Rate, Retention Interval, Segment Position, and Serial Position

\begin{tabular}{|c|c|c|c|c|c|c|c|c|c|c|c|c|}
\hline \multirow{3}{*}{$\begin{array}{l}\text { Trial } \\
\text { Type } \\
\end{array}$} & \multirow[b]{3}{*}{ Rate } & \multirow{3}{*}{$\begin{array}{l}\text { Retention } \\
\text { Interval }\end{array}$} & \multicolumn{10}{|c|}{ Segment Position } \\
\hline & & & \multicolumn{5}{|c|}{ First } & \multicolumn{5}{|c|}{ Second } \\
\hline & & & 1 & 2 & 3 & 4 & $M$ & 1 & 2 & 3 & 4 & $M$ \\
\hline \multicolumn{13}{|c|}{ Precue Condition, Fast First $(N=4)$} \\
\hline "Switch" & Fast & $\begin{array}{r}4 \\
12\end{array}$ & $\begin{array}{l}.833 \\
.333\end{array}$ & $\begin{array}{l}.333 \\
.333\end{array}$ & $\begin{array}{l}.500 \\
.167\end{array}$ & $\begin{array}{l}.250 \\
.583\end{array}$ & $\begin{array}{l}.479 \\
.354\end{array}$ & $\begin{array}{l}.583 \\
.667\end{array}$ & $\begin{array}{l}.583 \\
.667\end{array}$ & $\begin{array}{l}.750 \\
.583\end{array}$ & $\begin{array}{l}.667 \\
.667\end{array}$ & $\begin{array}{l}.646 \\
.646\end{array}$ \\
\hline & Slow & 4 & .750 & .500 & .417 & .667 & .583 & .917 & .750 & .750 & .917 & .833 \\
\hline & & 12 & .750 & .833 & .583 & .583 & .687 & .917 & .917 & .833 & .833 & .875 \\
\hline "No switch" & Fast & 4 & .750 & .528 & .500 & .667 & .611 & .806 & .667 & .694 & .833 & .750 \\
\hline & & 12 & .472 & .472 & .556 & .444 & .486 & .750 & .583 & .556 & .694 & .646 \\
\hline & Slow & 4 & .861 & .750 & .667 & .806 & .771 & .944 & .917 & .861 & .889 & .903 \\
\hline & & 12 & .778 & .556 & .750 & 639 & .681 & .806 & .694 & .833 & .861 & .799 \\
\hline \multicolumn{13}{|c|}{ Precue Condition, Slow First $(N=4)$} \\
\hline "Switch" & Fast & 4 & .583 & .417 & .417 & .750 & .542 & .667 & .500 & .583 & .667 & .604 \\
\hline & & 12 & .917 & .333 & .250 & .333 & .458 & .500 & .333 & .417 & .417 & .417 \\
\hline & Slow & 4 & .917 & .583 & .750 & .667 & .729 & .833 & .667 & .667 & .750 & .729 \\
\hline & & 12 & .667 & .500 & .500 & .417 & .521 & .750 & .833 & .583 & .750 & .729 \\
\hline " No switch" & Fast & 4 & .667 & .583 & .472 & .639 & .590 & .750 & .472 & .444 & .667 & .583 \\
\hline & & 12 & .694 & .472 & .333 & .444 & .486 & .667 & .472 & .500 & .639 & .569 \\
\hline & Slow & 4 & .750 & .500 & .417 & 694 & .590 & .806 & .722 & .667 & .917 & .778 \\
\hline & & 12 & .694 & .639 & .472 & .583 & .597 & .750 & .583 & .639 & .833 & .701 \\
\hline \multicolumn{13}{|c|}{ Postcue Condition, Fast First $(N=4)$} \\
\hline "Switch" & Fast & 4 & .583 & .250 & .333 & .500 & .417 & .333 & .500 & .417 & .667 & .479 \\
\hline & & 12 & .250 & .167 & .333 & .250 & .250 & .250 & .333 & .167 & .167 & .229 \\
\hline & Slow & 4 & .750 & .500 & .250 & .583 & .521 & .667 & .417 & .667 & .500 & .563 \\
\hline & & 12 & .417 & .500 & .417 & .333 & .417 & .500 & .333 & .333 & .417 & .396 \\
\hline "No switch" & Fast & 4 & .500 & .444 & .417 & .472 & .458 & .444 & .306 & .361 & .694 & .451 \\
\hline & & 12 & .472 & .333 & .333 & .333 & .368 & .500 & .250 & .333 & .389 & .368 \\
\hline & Slow & 4 & .556 & .500 & .500 & .417 & .493 & .667 & .444 & .389 & .722 & .556 \\
\hline & & 12 & .444 & .278 & .417 & .306 & .361 & .583 & .500 & .500 & .556 & .535 \\
\hline \multicolumn{13}{|c|}{ Postcue Condition, Slow First $(N=4)$} \\
\hline "Switch" & Fast & 4 & .500 & .250 & .417 & .333 & .375 & .417 & .583 & .583 & .667 & .563 \\
\hline & & 12 & .500 & .250 & & .500 & .458 & & .500 & .417 & .417 & .458 \\
\hline & Slow & 4 & .833 & .417 & .500 & .583 & .583 & .500 & .417 & .250 & .583 & .438 \\
\hline & & 12 & .583 & .333 & .500 & .167 & .396 & .500 & .250 & .333 & .333 & .354 \\
\hline "No switch" & Fast & 4 & .444 & .417 & .250 & .361 & .368 & .667 & .361 & .472 & .611 & .528 \\
\hline & & 12 & .583 & .361 & .389 & .417 & .437 & .444 & .278 & .389 & .333 & .361 \\
\hline & Slow & 4 & .667 & .528 & .444 & .583 & .556 & .750 & .667 & .472 & .611 & .625 \\
\hline & & 12 & .500 & .528 & .528 & .389 & .486 & .667 & .528 & .444 & .639 & .569 \\
\hline \multicolumn{13}{|c|}{$75 \%$ Precue Condition, Fast First $(N=16)$} \\
\hline Switch & Fast & 4 & .583 & .292 & .250 & .354 & .370 & .354 & .271 & .333 & .458 & .354 \\
\hline & & 12 & .375 & .167 & .229 & .333 & .276 & .187 & .229 & .312 & .167 & .224 \\
\hline & Slow & 4 & .375 & .229 & .375 & .437 & .354 & .542 & .417 & .437 & .583 & .495 \\
\hline & & 12 & .479 & .333 & .354 & .333 & .375 & .375 & .271 & .417 & .396 & .365 \\
\hline No switch & Fast & 4 & .556 & .444 & .396 & .542 & .484 & .618 & .424 & .458 & .639 & .535 \\
\hline & & 12 & .528 & .354 & .403 & .389 & .418 & .444 & .354 & .437 & .451 & .422 \\
\hline & Slow & 4 & .722 & .618 & .576 & .708 & .656 & .806 & .708 & .681 & .840 & .759 \\
\hline & & 12 & .660 & .597 & .583 & .535 & .594 & .694 & .569 & .646 & .569 & .620 \\
\hline \multicolumn{13}{|c|}{$75 \%$ Precue Condition, Slow First $(N=16)$} \\
\hline Switch & Fast & 4 & .438 & .292 & .354 & .542 & .406 & .500 & .458 & .458 & .604 & .505 \\
\hline & & 12 & .396 & .250 & .188 & .333 & .292 & .542 & .417 & .500 & .458 & .479 \\
\hline & Slow & 4 & .625 & .479 & .396 & .458 & .490 & .479 & .250 & .333 & .479 & .385 \\
\hline & & 12 & .479 & .396 & .333 & .458 & .417 & .333 & .333 & .312 & .271 & .312 \\
\hline No switch & Fast & 4 & .611 & .458 & .437 & .528 & .509 & .778 & .576 & .611 & .799 & .691 \\
\hline & & 12 & .535 & .368 & .389 & .437 & .432 & .535 & .472 & .368 & .465 & .460 \\
\hline & Slow & 4 & .743 & .556 & .479 & .597 & .594 & .833 & .681 & .646 & .778 & .734 \\
\hline & & 12 & .618 & .493 & .521 & .556 & .547 & .785 & .604 & .618 & .646 & .663 \\
\hline
\end{tabular}

Note - Retention interval $=$ number of digits. 
conditions did not involve any cue switching but did involve the same letter and digit sequences at the same trial numbers as did the switch trials in the $75 \%$ precue condition. Note that, as in our previous studies (see, e.g., Healy et al., 1987), we defined retention interval in terms of the number of interpolated digits, rather than the amount of elapsed time, because earlier studies (e.g., Waugh \& Norman, 1965) have shown that the number of interfering items has a larger effect on retention than does the duration of the interpolated time period. The results are summarized in Table 1 in terms of proportions of correct responses as a function of all seven factors in the experiment. The standard error of the mean proportions in Table 1 was .055 for the $75 \%$ precue condition and .108 for the precue and postcue conditions, as determined by separate ANOVAs for those conditions.

On the basis of previous findings with the partial report version of the distractor task (Cunningham et al., 1984; Healy et al., 1987; Lee \& Estes, 1981), we expected to find overall a steep retention function, symmetrical bow-shaped serial position functions, and an advantage for the most recently presented segment of letters. Likewise, our previous manipulations of cuing condition and exposure rate (Healy et al., 1987) led us to predict superior performance on the precue condition and an advantage for the slow rate of presentation, especially in the precue condition. On the assumption that our manipulation of trial type was successful, we also predicted an advantage for the no-switch trials over the switch trials in the $75 \%$ precue condition, especially with the slow exposure rate. All these predictions were confirmed. Of greatest interest was whether the retention function would be less steep when secondary memory encoding was reduced for the switch trials of the $75 \%$ precue condition. We found, however, that the retention function in that case was similar to that in the other conditions.

More specifically, the recall cue at the start of a trial aided retention $[F(2,42)=12.95, p<.001]$, as in the previous experiments, but it had a greater benefit when it reliably predicted the recall cue at the end of a trial than when it did not: With equal weight given to the "switch" and "no-switch" trials, the proportion of correct responses was greatest in the precue condition (.637), next largest in the $75 \%$ precue condition (.476), and smallest in the postcue condition (.451). Most crucially, the effect of trial type ("switch" or "no switch") was very large in the $75 \%$ precue condition but considerably smaller in the precue and postcue conditions; there was a significant main effect of trial type $[F(1,42)=29.84, p<$ $.001]$, as well as an interaction of cue condition and trial type $[F(2,42)=13.08, p<.001]$. The switch trials in the $75 \%$ precue condition (.381) yielded a lower percentage correct than did the corresponding trials in either the precue (.615) or the postcue (.431) conditions, but the no-switch trials in the $75 \%$ precue condition (.570) yielded a percentage correct midway between those for the corresponding trials in the precue (.659) and postcue (.470) conditions. It is particularly interesting to note that per- formance on the switch trials of the $75 \%$ precue condition, although relatively poor, was nonetheless considerably above chance (.250; see Cunningham et al., 1984, pp. 585-586, for a discussion of the derivation of the chance probability), suggesting that some representation of the segment not cued was stored in short-term memory. However, it is also important to note that performance on the no-switch trials of the $75 \%$ precue condition, although quite good, was nonetheless somewhat worse than that on the corresponding trials of the precue condition, suggesting that enhanced encoding was not applied as extensively to the segment indicated by the initial precue in the $75 \%$ precue condition.

As in Experiments 1 and 2 of the study by Healy et al. (1987), the proportion of correct responses declined as the retention interval increased from 4 to 12 digits in the precue condition ( 4 digits, $.670 ; 12$ digits, .603 ), the postcue condition ( 4 digits, $.498 ; 12$ digits, .403 ), and the $75 \%$ precue condition (4 digits, $.520 ; 12$ digits, .431$)[F(1,42)$ $=29.98, p<.001]$. Although a lower level of recall was present on the switch trials than on the no-switch trials, the decline in recall level with increases in retention interval was equivalent for the switch and no-switch trials, as illustrated in Figure 1, which presents the proportions of correct responses as a function of retention

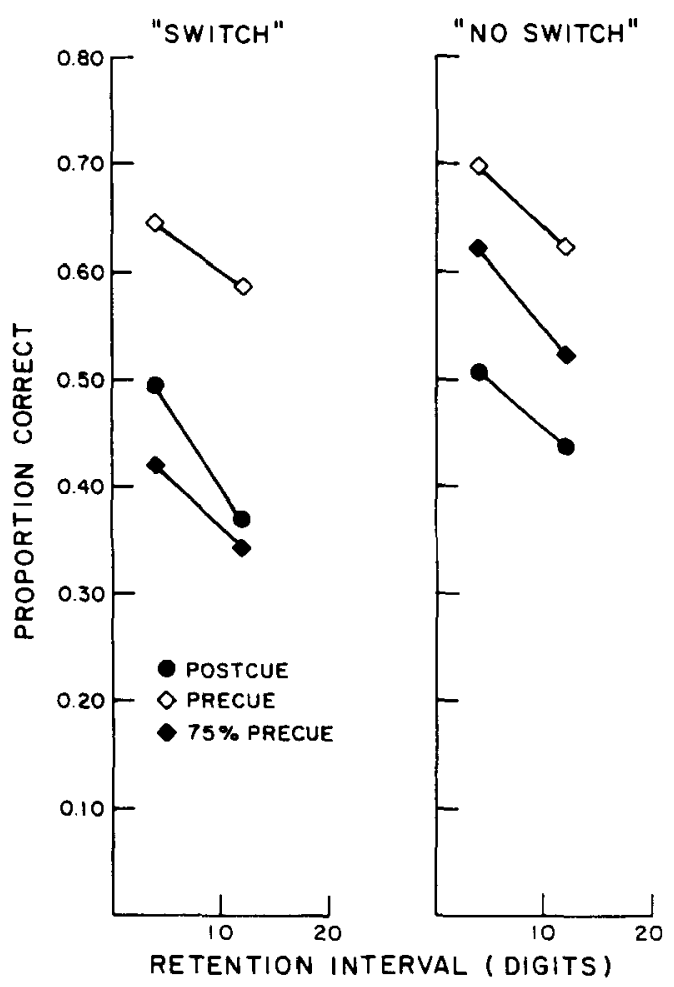

Figure 1. Proportions of correct responses in Experiment 1, as a function of retention interval and trial type for the precue condition (unfilled diamonds), the postcue condition (filled circles), and the $75 \%$ precue condition (filled diamonds). 


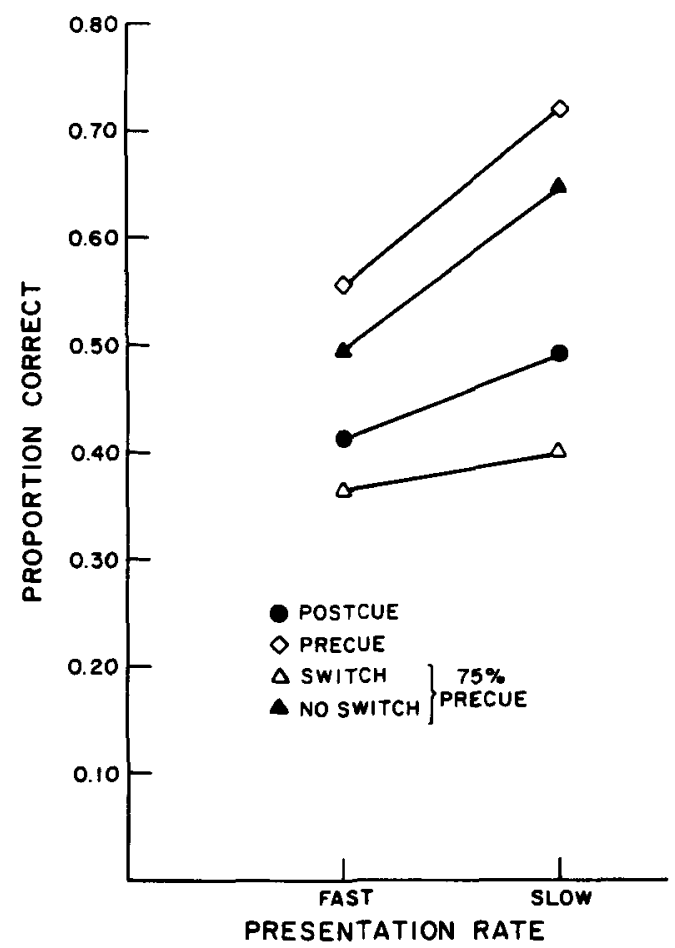

Figure 2. Proportions of correct responses in Experiment 1, as a function of rate for the precue condition (unfilled diamonds), the postcue condition (filled circles), the switch trials of the $75 \%$ precue condition (unfilled triangles), and the no-switch trials of the $75 \%$ precue condition (filled triangles).

interval and trial type for the precue condition (unfilled diamonds), the postcue condition (filled circles), and the 75\% precue condition (filled diamonds).

As in Experiment 2 of the study by Healy et al. (1987), presenting trials at the slow rate of presentation facilitated performance relative to the fast rate in the precue condition (fast, .554; slow, .719), the postcue condition (fast, .411 ; slow, .490 ), and the $75 \%$ precue condition (fast, .429 ; slow, .522) $[F(1,42)=53.83, p<.001]$. But the slower rate was more effective when the preliminary cue allowed for improved secondary memory encoding, as in the precue condition and on the no-switch trials of the $75 \%$ precue condition; the three-way interaction of rate, trial type, and cue condition was small but significant $[F(2,42)$ $=3.72, p=.032$ ]. On the switch trials of the $75 \%$ precue condition, there was very little improvement in performance because of increased exposure rate, which had been predicted on the assumption that secondary memory encoding would be reduced in that case. Figure 2 illustrates the effect of rate for the precue condition (unfilled diamonds), for the postcue condition (filled circles), and, separately, for the switch trials (unfilled triangles) and the noswitch trials (filled triangles) of the $75 \%$ precue condition.

Also, as in Experiments 1 and 2 of the study by Healy et al. (1987), the serial position functions were generally bow shaped and nearly symmetrical in the precue condition (Position 1, .735; Position 2, .584; Position 3, .566; Position $4, .661$ ), the postcue condition (Position 1, .530;
Position 2, .398; Position 3, .411; Position 4, .464), and the $75 \%$ precue condition (Position 1, .548; Position 2, .418; Position 3, .432; Position 4, .505) $[F(3,126)=$ $39.32, p<.001$ ]. In addition, there was a segment recency advantage $[F(1,42)=19.25, p<.001]$; the proportion of correct responses was greater for the second segment than for the first in the precue condition (second segment, .701; first segment, .573), the postcue condition (second segment, .467; first segment, .434), and the $75 \%$ precue condition (second segment, .500; first segment, .451). The shape of the serial position function depended to some extent on the segment position and the trial type. The two-way interaction of segment position and serial position was relatively small but significant $[F(3,126)=6.75, p<.001]$, as was the three-way interaction of segment position, trial type, and serial position $[F(3,126)=5.90, p<.001]$. Figure 3 presents the proportions of correct responses as a function of serial position and segment position for the precue condition (unfilled diamonds), the postcue condition (filled circles), and, separately, for the switch trials (unfilled triangles) and the no-switch trials (filled triangles) of the $75 \%$ precue condition.

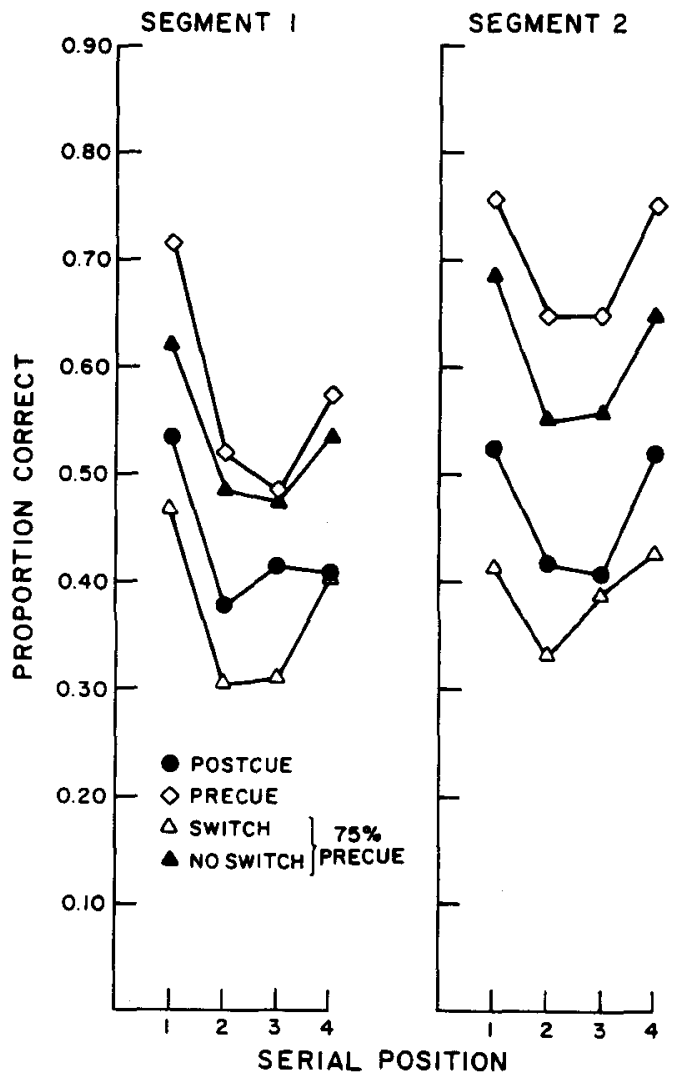

Figure 3. Proportions of correct responses in Experiment 1, as a function of serial position and segment position for the precue condition (unfilled diamonds), the postcue condition (filled circles), the switch trials of the $75 \%$ precue condition (unfilled triangles), and the no-switch trials of the $75 \%$ precue condition (filled triangles). 
There were in addition relatively small but significant two-way interactions of retention interval and serial position $[\mathrm{F}(3,126)=9.51, p<.001]$, and of rate and rate order $[F(1,42)=4.21, p=.046]$, along with two small but significant four-way interactions involving exposure rate, one in conjunction with cue condition, rate order, and segment position $[F(2,42)=3.43, p=.042]$, and the other in conjunction with trial type, segment position, and serial position $[F(3,126)=2.89, p=.038]$. There were no other significant effects.

\section{EXPERIMENT 2}

The unexpected absence of a difference in the slope of the retention functions between the switch and no-switch trials of the $75 \%$ precue condition of Experiment 1 may be due to a number of factors, including the fact that we did not employ a retention interval of 0 digits. The phenomenon of very rapid forgetting reported by Muter (1980) and Sebrechts et al. (1989) appears to be largely a function of the drop in performance from the 0 -sec retention interval to the next interval (i.e., the 2 -sec or 4-sec interval). After the initial decline from the 0 -sec to the next retention level, the slope of the retention function across the remaining delay intervals is approximately parallel for Muter's testing paradigm and for the traditional distractor paradigm (see, e.g., a comparison of the retention functions obtained by Muter, 1980, p. 176, in his Experiments 2 and 3). In Experiment 2, we therefore included a 0-digit retention interval along with the digitfilled delay intervals used in Experiment 1.

As in Experiment 1, the purpose of Experiment 2 was to isolate and study the operation of primary memory processes in the short-term recall of order information. Unlike in Experiment 1, we did not use switch trials to vary expectancy and, thereby, reduce the influence of elaborative encoding. There are three problems with the switch technique employed in Experiment 1 and in previous work (Muter, 1980; Sebrechts et al., 1989). First, this technique uses only a small number of critical trials. Although we used many more critical trials than did previous investigators, only $25 \%$ of the experimental trials were critical ones in Experiment 1. Because of this sampling procedure, the data obtained for each subject are not as reliable as those obtained with the use of a full set of trials. Second, the switch procedure introduces an element of surprise, which may lead to confusion among the subjects as to the task required on a critical trial. Muter, in his Experiment 2, Sebrechts et al., and we in our Experiment 1 attempted to minimize surprise by informing subjects in advance of the existence of switch trials. Nevertheless, it is possible that subjects still exhibited some confusion, although subjects made very few noncompliance errors, or responses that included letters that were not in the subset of the cued segment. Third, we found in Experiment 1 that subjects' performance was lower on the no-switch trials of the $75 \%$ precue condition than on the corresponding trials of the standard precue condition. This result suggests that subjects might not have focused exclusively on the segment indicated by the precue, or might not have ignored the uncued segment, when switch trials were intermixed with no-switch trials. Thus, there is the possibility that more extensive encoding occurred for uncued segments in the no-switch trials of the $75 \%$ precue condition than for the uncued segments in the standard precue condition.

In Experiment 2, we used the same stimulus arrangement on each trial as we used in Experiment 1; that is, we presented two four-letter segments, at short and long exposure rates, and in both precue and postcue conditions. Our strategy, as before, was to isolate primary memory processing by studying recall performance on the uncued segments. In contrast to the partial report procedure used in Experiment 1 and in our earlier work (Cunningham et al., 1984; Healy et al., 1987), we used a full report procedure that required subjects to recall both the noncued and cued letter segments on each trial in a specific order. The subjects were told that they must always recall the noncued segment before the cued segment. To induce the subjects to focus on the cued segment and to establish that as the more important segment, we told subjects that they were participating in a competitive exercise and would receive a point for every cued, or target, segment they recalled correctly. We indicated that the noncued segment merely represented a distractor and that no points would be awarded for recall of that segment, despite the fact that it was to be recalled first. Though we required immediate recall of the noncued letter segment, by deemphasizing its relative importance and treating it as a distractor, we attempted to reduce elaborative encoding of the noncued segment.

One advantage of this full report technique is that the element of surprise is eliminated because the same procedure is used on every trial. A second advantage is that in this procedure every trial is a critical trial so that no data are lost. Hence, the first two problems of the switch technique described above are eliminated in the full report method. The third problem, which concerns whether the subjects focus on the cued segment, might still exist. For the full report procedure to be successful in isolating primary memory, subjects must treat the cued segment as being of more importance for later recall than the noncued segment and use elaborative encoding only on the more important segment. Assuming that subjects focus on the cued segment, as instructed, we predict that the comparison of the precue and postcue conditions will show opposite effects in recall of the cued (or target) and noncued (or distractor) segments. For the target segment, as in previous studies, the precue condition should be superior to the postcue condition, whereas for the distractor segment, the precue condition should produce a lower level of recall (and perhaps a steeper retention function) than the post- 
cue condition, because the precue condition encourages the subject to attend maximally to the target segment and, thus, to ignore maximally the distractor segment.

\section{Method}

The method of Experiment 2 was equivalent to that of Experiment 1 , except as specifically noted.

Subjects. Twenty-four male and female undergraduate students attending introductory psychology classes at St. Lawrence University in Canton, New York volunteered to participate as subjects and received extra course credit. There were 12 subjects in each of the exposure rate conditions of $500 \mathrm{msec}$ and $1,000 \mathrm{msec}$.

Apparatus and Stimulus materials. A Gorilla Hi-Resolution Green Monochrome monitor, controlled by an IBM Personal Computer, was used to display the stimuli visually. The characters were $6 \times 3 \mathrm{~mm}$. Each trial began with the display of two hyphens appearing rapidly in succession. Depending on the experimental condition to which subjects were assigned, the fast exposure rate or the slow exposure rate, the subjects viewed each character for either $500 \mathrm{msec}$ or $1,000 \mathrm{msec}$. The two-hyphen prompt had a combined display time of $1,000 \mathrm{msec}$ in the 500 -msec rate condition and $2,000 \mathrm{msec}$ in the 1,000 -msec rate condition. The time interval between the presentation of stimuli on two successive trials was $24 \mathrm{sec}$, with a warning buzzer prompt after each $12 \mathrm{sec}$.

An experimental trial consisted of the presentation of two fourletter segments followed by digit-filled retention intervals of 0,4 , or 12 digits (or 0,2 , or $6 \mathrm{sec}$ in the 500 -msec rate condition, and 0,4 , or $12 \mathrm{sec}$ in the 1,000 -msec rate condition). An exclamation point (!) marked the boundary between the first and second fourletter segments but, unlike in Experiment 1, there was no second exclamation point between the end of the second segment of letters and the digits. The second exclamation point was omitted in this experiment, to allow the immediate presentation of a recall cue in the 0-digit retention interval condition. The recall cues (" ." or ".:") indicated the target segment, which was to be recalled last on a particular trial

Design. Each subject in both rate-of-exposure conditions received a sequence of 96 experimental trials that was constructed to include four 24-trial blocks. Within each block of 24 trials, three withinsubjects factors were manipulated: cue condition, position of the target segment, and retention interval. Four tasks were defined by the combination of cue condition (precue or postcue) and segment position of the target (first or second). Each of the four tasks occurred six times per block, twice with each of the three retention intervals.

Each of the 24 pairs of four-letter permutations occurred once per block and once with each task across the four blocks, always at the same retention interval. The order of the 24 trials within each block was pseudorandom, with the constraint that the same retention interval could not occur successively on more than two trials. The position of each block was counterbalanced across the 12 subjects in each rate-of-exposure group according to a Latin square arrangement. There were 12 practice trials presented before the experimental trials

Procedure. The subjects were tested individually in sessions that lasted approximately $75 \mathrm{~min}$ in the case of the 500 -msec rate-ofexposure condition and $105 \mathrm{~min}$ for the 1,000-msec rate-of-exposure condition.

The subjects were informed that the cued segment was the target segment of a trial and that recalling the target segment correctly would result in accruing points for each trial. The subjects were also informed, however, that on each trial they had to recall the noncued segment first and then the cued or target segment, because the purpose of the experiment was to determine what effect recalling letters from a noncued segment first had on recall of the to-beremembered letters of the target segment. The noncued segment was always referred to by the experimenter as the nonindicated or distractor segment. The subjects were told that at the end of the study they would be informed of their total score, which would be based on recall of the target segments, and that they would receive a listing of the scores achieved by all subjects so that they could compare their performance with that of others in the experiment.

On each trial, the subjects were instructed to write down the four letters of the distractor segment followed by the four letters of the target segment. The subjects entered their responses on standard sheets of paper that included two horizontal linear arrays of four squares, each array representing one four-letter segment with one square allocated for each letter. The first horizontal array was labeled distractor for the noncued segment and the second array was labeled target for the cued segment. If the subjects achieved a criterion of correctly recalling two target segments in the 12 practice trials, they were permitted to continue to the experimental trials. All experimental subjects met this performance criterion. ${ }^{\prime}$ There was a short rest break of approximately $2 \mathrm{~min}$ at the end of the first and third 24-trial blocks while the experimenter prepared the computer to present the next block of 24 trials. A rest period of approximately $10 \mathrm{~min}$ was given at the end of the second block of experimental trials.

\section{Results}

As in Experiment 1, each of the four letters recalled in a segment was scored separately. There were two segments to be recalled on each trial-first the noncued, or distractor, segment, and second, the cued, or target, segment. A mixed-factor ANOVA was conducted on the proportion of correct responses, including one betweensubjects factor-exposure rate (fast or slow)-and five within-subjects factors--segment status (distractor or target), cue condition (precue or postcue), retention interval $(0,4$, or 12 digits), position of segment (first or second), and serial position within a segment $(1,2,3$, or 4). The results are summarized in Table 2 in terms of proportions of correct responses as a function of all six factors in the experiment. The standard error of the mean proportions in Table 2 was .034 , as determined by the ANOVA.

Again on the basis of previous findings with the partial report version of the distractor task, including the present Experiment 1, we expected to find overall a steep retention function, symmetrical bow-shaped serial position functions, a segment recency advantage, and an advantage for the slow presentation rate. On the assumption that our manipulation of segment status was successful, we also predicted superior performance on the target segment as opposed to the distractor segment, especially in the precue condition. These predictions were all confirmed. Of greatest interest was whether the retention function would be less steep when secondary memory encoding was reduced for the distractor trials in the precue condition. However, the retention function in that case was similar to that in the other conditions.

More specifically, as in Experiment 1, a slower exposure rate produced better recall $[F(1,22)=10.41, p=$ $.004]$. The proportion of correct responses was .450 in the 500 -msec condition and .604 in the 1,000 -msec condition. Also, as expected, there was a large recency ad- 
Table 2

Proportions of Correct Responses in Experiment 2 as a Function of Exposure Rate, Segment Status, Cue Condition, Retention Interval, Segment Position, and Serial Position

\begin{tabular}{|c|c|c|c|c|c|c|c|c|c|c|c|c|}
\hline \multirow{3}{*}{$\begin{array}{c}\text { Segment } \\
\text { Status }\end{array}$} & \multirow{3}{*}{$\begin{array}{c}\text { Cue } \\
\text { Condition } \\
\end{array}$} & \multirow{3}{*}{$\begin{array}{c}\text { Retention } \\
\text { Interval }\end{array}$} & \multicolumn{10}{|c|}{ Segment Position } \\
\hline & & & \multicolumn{5}{|c|}{ First } & \multicolumn{5}{|c|}{ Second } \\
\hline & & & 1 & 2 & 3 & 4 & $M$ & 1 & 2 & 3 & 4 & $M$ \\
\hline \multicolumn{13}{|c|}{ Exposure Rate, Fast $(N=12)$} \\
\hline \multirow[t]{6}{*}{ Distractor } & Precue & 0 & .594 & .406 & .354 & .469 & .456 & .635 & .594 & .615 & .677 & .630 \\
\hline & & 4 & .469 & .375 & .333 & .365 & .385 & .417 & .313 & .323 & .573 & .406 \\
\hline & & 12 & .323 & .240 & .313 & .292 & .292 & .354 & .365 & .260 & .375 & .339 \\
\hline & Postcue & 0 & .500 & .375 & .292 & .396 & .391 & .781 & .698 & .729 & .813 & .755 \\
\hline & & 4 & .406 & .344 & .323 & .427 & .375 & .552 & .354 & .458 & .656 & .505 \\
\hline & & 12 & .396 & .406 & .260 & .344 & .352 & .365 & .229 & .323 & .417 & .333 \\
\hline \multirow[t]{6}{*}{ Target } & Precue & 0 & .646 & .490 & .438 & .583 & .539 & .719 & .573 & .552 & .698 & .635 \\
\hline & & 4 & .510 & .333 & .396 & .490 & .432 & .573 & .385 & .385 & .635 & .495 \\
\hline & & 12 & .521 & .365 & .406 & .417 & .427 & .427 & .417 & .427 & .448 & .430 \\
\hline & Postcue & 0 & .573 & .438 & .417 & .573 & .500 & .667 & .563 & .573 & .750 & .638 \\
\hline & & 4 & .438 & .365 & .313 & .458 & .393 & .469 & .365 & .427 & .573 & .458 \\
\hline & & 12 & .344 & .313 & .260 & .292 & .302 & .344 & .313 & .240 & .396 & .323 \\
\hline \multicolumn{13}{|c|}{ Exposure Rate, Slow $(N=12)$} \\
\hline \multirow[t]{6}{*}{ Distractor } & Precue & 0 & .604 & .563 & .552 & .646 & .591 & .802 & .740 & .740 & .802 & .771 \\
\hline & & 4 & .490 & .417 & .406 & .396 & .427 & .552 & .531 & .500 & .625 & .552 \\
\hline & & 12 & .417 & .448 & .302 & .427 & .398 & .500 & .375 & .469 & .531 & .469 \\
\hline & Postcue & 0 & .604 & .552 & .552 & .542 & .563 & .854 & .813 & .771 & .885 & .831 \\
\hline & & 4 & .531 & .500 & .479 & .479 & .497 & .667 & .615 & .563 & .708 & .638 \\
\hline & & 12 & .521 & .479 & .417 & .479 & .474 & .615 & .500 & .500 & .583 & .549 \\
\hline \multirow[t]{6}{*}{ Target } & Precue & 0 & .729 & .625 & .625 & .688 & .667 & .844 & .719 & .729 & .833 & .781 \\
\hline & & 4 & .635 & .583 & .573 & .573 & .591 & .719 & .615 & .615 & .760 & .677 \\
\hline & & 12 & .656 & .542 & .542 & .625 & .591 & .688 & .604 & .604 & .708 & .651 \\
\hline & Postcue & 0 & .688 & .656 & .615 & .688 & .661 & .792 & .760 & .740 & .823 & .779 \\
\hline & & 4 & .698 & .563 & .594 & .573 & .607 & .667 & .635 & .573 & .698 & .643 \\
\hline & & 12 & .583 & .500 & .510 & .479 & .518 & .563 & .563 & .563 & .625 & .578 \\
\hline
\end{tabular}

Note-Retention interval $=$ number of digits.

vantage that was based on the position of the segment $[F(1,22)=38.72, p<.001]$. The proportion of items recalled in the more recently presented second segment was .578 , whereas the comparable figure for the first segment was .476 .

Our previous research (Cunningham et al., 1984; Healy et al., 1987) indicated that a precue should result in recall superior to that for a postcue when testing the target segment. However, in the context of recalling the distractor segment, we expected poorer performance in the precue condition because of reduced encoding. As predicted, cue condition differentially affected recall in the distractor and target segments $[F(1,22)=7.33, p=.012]$. For the target segment, the proportion of correct responses was higher in the precue condition (.576) than in the postcue condition (.533), whereas for the distractor segment, performance in the precue condition (.476) was inferior to that in the postcue condition (.522). These means also reveal that, especially in the precue condition, performance was superior on the target segment than on the distractor segment, even though the distractor segment was recalled first. This finding illustrates the success of our instructional manipulation.

Recall performance showed a large decline as the length of the retention interval increased in both the distractor segment (0 digits, .623; 4 digits, .473 ; and 12 digits, .401 ) and the target segment ( 0 digits, $.650 ; 4$ digits, .537 ; and
12 digits, .478) $[F(2,44)=49.22, p<.001]$. Also, recall across the retention intervals varied as a function of the position of the segment at the time of presentation $[F(2,44)=15.58, p<.001]$. The retention function was generally higher and the slope of the function steeper for the second segment ( 0 digits, .728; 4 digits, .547; and 12 digits, .459) than for the first segment ( 0 digits, .546 ; 4 digits, .464; and 12 digits, .419). Of interest, however, is whether this relationship is affected by the importance assigned to each segment. If segment status affects degree of encoding, different retention functions might emerge for the first and second segments when they are recalled as targets and distractors. There was no two-way interaction of segment status with either segment position or retention interval. However, Figure 4 illustrates the small but significant three-way interaction of segment status, segment position, and retention interval $[F(2,44)=3.35, p=$ .043]. As can be seen in Figure 4, at the 0-digit retention interval, recall of the second segment is higher than that of the first segment, irrespective of segment status. But at the longest retention interval, recall of the second segment is no longer superior when it serves as the distractor. Thus, the retention function for this condition is steeper than that of the other conditions. At the longest retention interval, recall of the target segment is superior to that of the distractor segment, irrespective of the position of the segment during stimulus presentation. Better retention of 


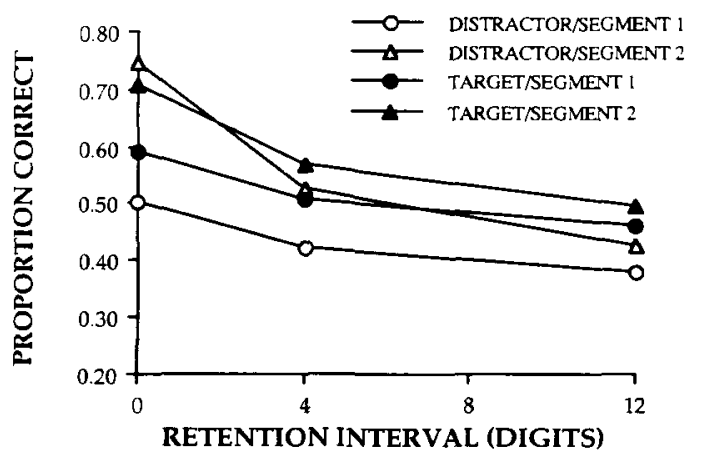

Figure 4. Proportions of correct responses in Experiment 2, as a function of retention interval when the distractor segment was Segment 1 (unfilled circles) or Segment 2 (unfilled triangles) and the target segment was Segment 1 (filled circles) or Segment 2 (filled triangles).

the target segments at the longest retention interval suggests that more extensive encoding was provided to the more important, cued segment. However, the three-way interaction of retention interval, segment status, and cue condition was not significant. That interaction is crucial according to predictions based on work by Muter (1980) and Sebrechts et al. (1989), because elaborative encoding processes should be reduced the most (and, hence, the retention function should be the steepest) for the distractor segment in the precue condition. In fact, to the contrary, the retention functions were very similar for the four combinations of segment status and cue condition.

The serial position functions were generally bow shaped and symmetrical for the distractor (Position 1, .539; Position 2, .468; Position 3, .451; Position 4, .538) and the target segment (Position 1, .604; Position 2, .512; Position 3, .505; Position 4, .599); there was a large main effect of serial position $[F(3,66)=39.42, p<.001]$. The shape of the function was affected by the position of the segment at presentation $[F(3,66)=11.38, p<$ $.001]$. There was a larger primacy advantage than recency advantage in recall of the first segment (Position 1, .536; Position 2, .453; Position 3, .428; Position 4, .487), whereas the advantage was reversed in the second segment (Position 1, .607; Position 2, .526; Position 3, .528; Position $4, .650$ ). This segment $\times$ serial position interaction was also affected to a small extent by exposure rate and cue condition $[F(3,66)=3.49, p=.020]$. The level and shape of the serial position function varied to a small extent with exposure rate and retention interval $[F(6,132)$ $=2.57, p=.022]$.

\section{GENERAL DISCUSSION}

The aim of this study was to reduce secondary memory processes, or elaborative encoding, and to isolate primary memory processes in the context of a variant of the distractor paradigm that included two distinct letter segments. This aim was achieved in both experiments by ma- nipulating either the recall expectancy or the importance of each of the two segments. In Experiment 1, we compared three conditions in which we varied the subjects' expectancy as to which one of the two segments was to be recalled on a given trial. In the precue condition, the subjects were told in advance which segment would be tested at the end of the distractor period. Thus, the subjects were led to expect in advance the segment that would later be requested for recall. In the postcue condition, the subjects were not informed in advance, and thus they had no differential expectancy regarding which segment would be tested. In the $75 \%$ precue condition, as in the precue condition, the subjects were given an advance precue concerning which segment would be tested, but on $25 \%$ of the trials (the switch trials), the precue was not a valid predictor. Thus, on the switch trials, the segment tested was not the one expected on the basis of the precue. Hence, expectancy concerning recall of the tested segment was high in the precue condition, intermediate in the postcue condition, and low in the switch trials of the $75 \%$ precue condition. Primary memory should have been isolated to the greatest extent on the switch trials of the $75 \%$ precue condition because the subjects in that case were tested on the segment that was not expected. The subjects on such trials should have engaged in little elaborative encoding of the unexpected segment. Indeed, we found that the level of performance on the switch trials of the $75 \%$ precue condition was lower than that on the corresponding trials of the precue and postcue conditions. However, it should be noted that the level of performance on the no-switch trials of the $75 \%$ precue condition, although higher than that on the postcue condition, was lower than that on the precue condition. This finding suggests that there was elaborative encoding of the precued segment but that it was reduced in the $75 \%$ precue condition relative to that in the standard precue condition. It also suggests that although elaborative encoding (or secondary memory processes) was greatly reduced for the uncued segment in the $75 \%$ precue condition, subjects may have applied some elaborative encoding in that case.

In Experiment 2, all subjects on all trials were tested on both of the two letter segments, with the noncued, or distractor, segment always recalled prior to the cued, or target, segment. Again both precue and postcue conditions were included. It was predicted that for the target segment, as previously, the level of recall performance would be higher in the precue condition, in which elaborative encoding of that segment would be likely, than in the postcue condition. In the postcue condition, the two segments would be encoded to the same extent, because at the time of encoding it was uncertain which of the two would be signaled as the target. In contrast, it was expected that for the distractor segment, the level of recall performance would be higher in the postcue condition than in the precue condition. In the postcue condition, the target segment would not be identified prior to presentation, so subjects would be forced to do more extensive encoding of both segments. In the precue condition, the dis- 
tractor segment would have little importance for recall, so that the subject should rely on primary memory processes and use few secondary elaborative encoding processes with respect to this segment. Indeed, the expected interaction between cue condition and segment status was observed.

\section{Very Rapid Forgetting}

Research by Muter (1980) and Sebrechts et al. (1989) has indicated very rapid forgetting under conditions in which subjects do not expect to recall after a filled distractor interval. However, although we found low levels of retention when subjects did not expect to recall a given segment or that segment was given a low importance, we did not find that forgetting of the segment was more rapid. In order to assess the time course of forgetting information from memory, both Muter and Sebrechts et al. employed two different scoring procedures: According to the strict method of scoring, all to-be-remembered items on a given trial had to be recalled in the order in which they were shown. In contrast, according to the lenient method, item recall was evaluated without regard for the order in which the items were presented. The marked decline in performance over brief periods of time was most dramatically demonstrated with the strict scoring method, in which performance approached the floor by approximately $4 \mathrm{sec}$. In the present study, only order information had to be recalled, because the same items were shown in each segment on every trial. Hence, the lenient scoring method used by Muter and Sebrechts et al. could not be applied. However, the method of scoring that we used in presenting the results above was relatively lenient, because each letter was scored separately. The strict method of scoring can be applied to our experimental situation if a segment is scored as correct only if all the items were recalled in the correct order. To underscore the low level of retention and to examine the rate of forgetting present with our techniques, we rescored the data from Experi-

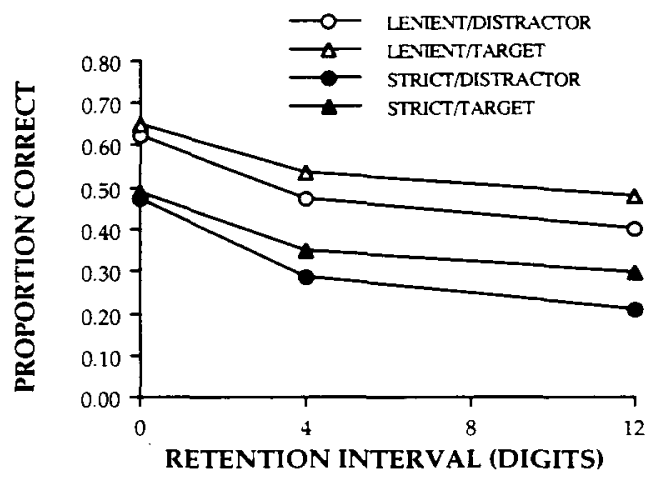

Figure 5. Proportions of correct responses in Experiment 2, as a function of retention interval when the lenient scoring method was applied to the distractor segment (unfilled circles) or the target segment (unfilled triangles) and when the strict method was applied to the distractor segment (filled circles) or the target segment (filled triangles).

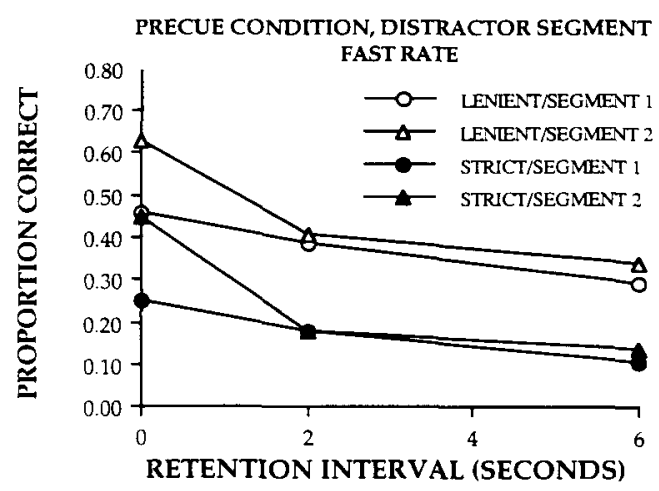

Figure 6. Proportions of correct responses in Experiment 2 on the distractor segment at the fast $(500-\mathrm{msec})$ exposure rate in the precue condition, as a function of retention interval (in seconds) when the lenient scoring method was applied to Segment 1 (unfilled circles) or Segment 2 (unfilled triangles) and when the strict scoring method was applied to Segment 1 (filled circles) or Segment 2 (filled triangles).

ment 2 , using the strict method. The retention functions for both lenient and strict methods of scoring are shown in Figure 5 for both the target and the distractor segments. Note that the level of performance for the distractor segment under the strict scoring method is very low at the longest retention interval. To obtain the best estimate of forgetting from primary memory, we examined the strict and lenient scoring of the distractor segment at the fast $(500-\mathrm{msec})$ rate of exposure in the precue condition only. Figure 6 presents these retention functions, separately, for situations in which Segment 1 and Segment 2 serve as the distractor. The separation by segment position seems necessary, because it is only Segment 2 that is followed immediately by the retention interval. The retention interval in Figure 6 is presented in seconds, rather than digits, to facilitate comparison with the earlier studies of Muter and Sebrechts et al. Note the comparable rates of forgetting exhibited by the retention functions obtained by using the two different scoring techniques.

In summary, on the basis of our findings as well as those of Muter (1980) and Sebrechts et al. (1989), it is evident that when secondary memory processes are reduced in tests of short-term memory, the level of retention is greatly depressed. However, our findings do not support the contention that the rate of forgetting is much more rapid than that proposed in earlier studies in which the standard distractor paradigm was used. At a minimum, our findings indicate that very rapid forgetting of the type found by Muter and Sebrechts et al. cannot be generalized to the recall of order information of known items. Moreover, a careful analysis of our findings and those of Muter and Sebrechts et al. indicates that the crucial difference occurs at the 0 -sec retention interval. Recall performance is very high (close to the ceiling) in the studies by Muter and Sebrechts et al. but is at a much lower level in the present study at that point. It is possible that the very rapid forgetting function found by Muter and Sebrechts et al. is attributable to an aspect of their procedure that may 
elevate the performance level at the 0 -sec retention interval. In fact, the level of performance at the 0 -sec retention interval in the studies by Muter and Sebrechts et al. was very similar to that in the earlier study by Murdock (1961), who used the standard distractor paradigm with no reduction in the subjects' expectancy of a recall test. This elevated level of performance presumably occurred because in the studies by Muter and Sebrechts et al. there was no reason for subjects' expectancy to be reduced at the 0-sec delay; that is, delay interval was confounded with expectancy to recall. At the 0-sec delay, the critical trials could not be discriminated by the subjects from maintenance trials, which constituted the vast majority (75\%-84\%) of experimental trials. On maintenance trials, the to-be-remembered material was tested with no interpolated counting activity (only a blank screen for 1.5 or $2 \mathrm{sec}$ ) after stimulus presentation. In contrast, on the critical trials at the longer delays, subjects should have reduced expectancy for recall because of their experience with the large number of counting trials $(17 \%-20 \%$ of experimental trials) on which no recall was required. Our procedure overcame this problem because our immediate test limited secondary memory encoding by the subjects in the same way as did testing at longer retention intervals.

To assess whether the overall rate of forgetting was more rapid when secondary memory processes were reduced, we examined whether the retention function interacted with the experimental conditions used to manipulate either subjects' recall expectancy or the importance of the segment that was to be recalled. Although this method for assessing forgetting has been used before (see, e.g., Slamecka \& McElree, 1983), it has been criticized by investigators (see, e.g., Loftus, 1985b) who have proposed alternative methods. Those alternatives, however, have also been subjected to criticism (see, e.g., Slamecka, 1985; but also see Loftus, 1985a). In any event, neither the method that we used nor the alternative is able to separate the contributions of primary and secondary memory processes to the overall retention functions. A mathematical model is required for this purpose, and the Estes (1972; Lee \& Estes, 1981) perturbation model is ideally suited for an assessment of the rate of forgetting from primary memory.

\section{Cuing Order Information}

Attempts to fit the Estes perturbation model to the data from the critical test condition. The general findings regarding the retention of order information in both experiments replicated previous work (see, e.g., Cunningham et al., 1984; Healy et al., 1987). Specifically, there was a drop in performance as retention interval increased, an advantage for the most recently presented segment, and serial position functions that were bow shaped and nearly symmetrical at each retention interval. These findings are compatible with the Estes (1972; Lee \& Estes, 1981) perturbation model, according to which short-term memory codes for order information are arranged in a hierarchy with three levels, including the position of the item within a segment, the segment containing the item, and, at the highest level, the specific trial on which the segment occurred. There is a repeated reactivation (i.e., passive, or automatic, rehearsal; see Cunningham et al., 1984) of the hierarchy of codes, such that at each reactivation there is some probability that the relative position of neighboring items, segments, or trials is perturbed. This model was modified by Estes (1983) to account for performance in both precue and postcue conditions over long retention intervals. The mathematical equations underlying the modified perturbation model were described in detail by Healy et al. (1987), who considered various alternative versions of the perturbation model and validated the modified version as providing the best fit to both cuing conditions. The modified perturbation model includes two free parameters: The first parameter, reflecting primary memory rehearsal processes, is theta, which is the probability of a perturbation at either the item or the trial level. (There are actually three different theta parameters, one for each level in the hierarchy. However, perturbations at the segment level are not possible in our experiments, and our previous work indicated no need to distinguish between the values of theta for the item and trial levels; see Cunningham et al., 1984.) The second parameter, reflecting secondary-memory encoding processes, is alpha, which represents the probability that the code for an item's position, segment, or trial would continue to be subject to the perturbation process. Thus, $1-\alpha$ is equal to the probability of storing the intial encoding of the item's position, segment, or trial in secondary memory, where the code would no longer be subject to the perturbation process. Healy et al. compared the modified perturbation model's predictions with the observed serial position functions for each segment at each retention interval of the precue and postcue conditions. The best fits were obtained when the primary-memory rehearsal parameter theta was set equal to .04 in both conditions and the secondarymemory encoding parameter alpha was set equal to .985 in the postcue condition and .975 in the precue condition. The value of .04 for theta was also obtained for analogous conditions in the earlier studies by Lee and Estes (1981) and Cunningham et al. (1984).

The primary question of interest in the present study is whether the modified version of the perturbation model can also account for performance when secondary-memory elaborative encoding processes are reduced and, hence, primary memory processes are isolated as much as possible. These conditions were realized at the fast exposure rate in the switch trials of the $75 \%$ precue condition of Experiment 1 and in the distractor segment of the precue condition of Experiment 2, because the precuing in both of these conditions encouraged the subjects to attend maximally to the cued segment and, thus, ignore maximally the uncued segment. Experiment 1 included only two retention intervals, 4 digits and 12 digits, whereas Experiment 2 included three intervals, a 0-digit immediate test along with the two intervals also used in Experiment 1 . Figure 7 presents the serial position functions for both segment positions at the 4- and 12-digit retention in- 
SEGMENT 1

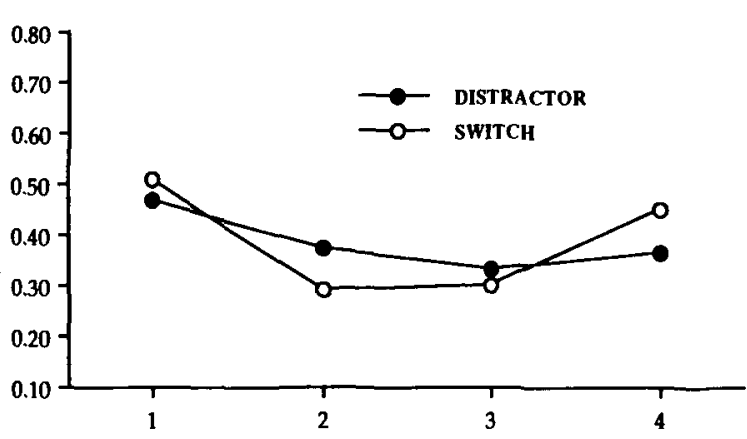

SEGMENT 2

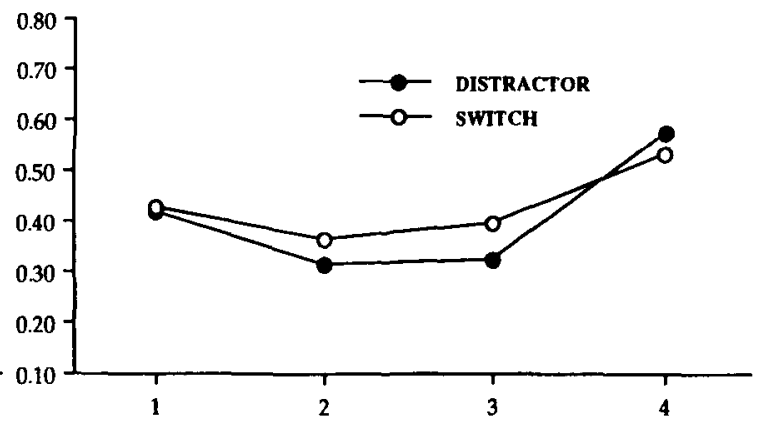

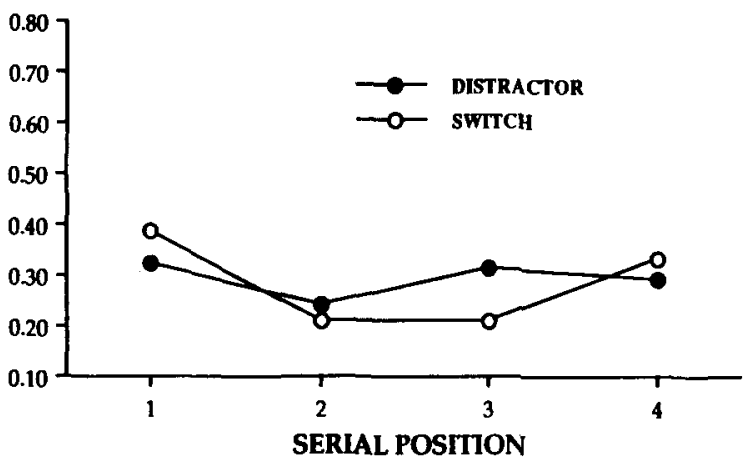

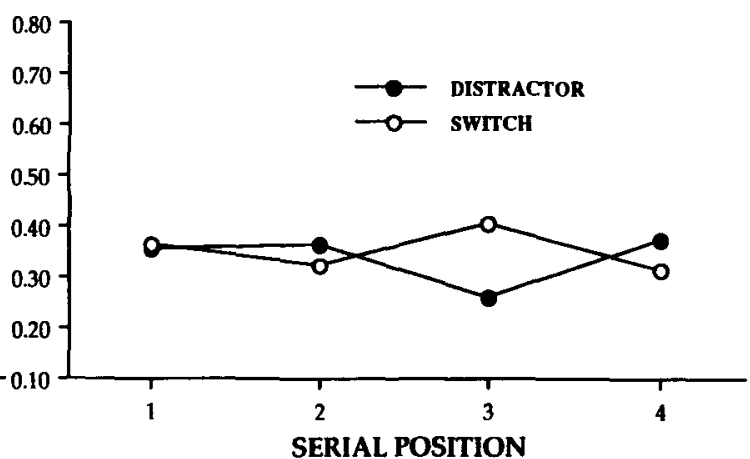

Figure 7. Proportions of correct responses, as a function of segment position, retention interval (4 digits and 12 digits only), and serial position for the switch trials of the 75\% precue condition of Experiment 1 (unfilled circles) and the distractor segment of the precue condition of Experiment 2 (filled circles) at the fast exposure rate.

tervals of the conditions in the two experiments in which primary memory processes were best isolated. To estimate the degree of discrepancy between these two functions, we calculated a root mean square deviation (RMSD) statistic, which is similar to a standard deviation. It yielded the value of .067 and, thus, indicated a close correspondence between the two sets of observed functions.

Because the two experiments yielded analogous patterns of results, we chose to fit the modified perturbation model only to the data from Experiment 2, which included the additional 0 -digit retention interval and more trials per subject in the critical test condition in which primary memory processes were best isolated. It is of crucial importance to determine whether the primary-memory rehearsal parameter theta or the secondary-memory encoding parameter alpha required adjustment in order to account for memory performance when elaborative encoding processes were reduced. When we kept theta constant at .04 (the value giving the best fit to both the postcue and the precue conditions in the study by Healy et al., 1987), we could not account for the very low levels of performance in the critical test condition. Even with alpha set equal to 1.000 (the maximum value, which eliminates the secondary-memory encoding component), the predicted proportions of correct responses exceeded the observed proportions, especially at the 0 -digit and 4 -digit retention intervals. Likewise, when we kept the secondary-memory encoding parameter alpha fixed at .985 (the value giving the best fit to the postcue condition in the study by Healy et al., 1987) and increased the value of the primarymemory rehearsal parameter theta, there was an important discrepancy between the observed and predicted data. The predicted level of performance in Segment 2 at the 0 -digit retention interval was much higher than the observed level.

Perhaps the low level of performance found for Segment 2 at the 0 -digit retention interval could be explained by noncompliance errors by the subjects, whose responses on some trials included letters that were not in the subset allowed for the given segment. To correct for these types of noncompliance errors and thereby provide a better test of the model, we computed the conditional proportions of correct responses, given that the subjects responded with a letter from the appropriate segment. However, even for these corrected data, the model still greatly overestimated the level of performance in Segment 2 at the 0 -digit retention interval.

Resolving the model's problems. Predicting performance when retention in the critical test condition is tested immediately (i.e., when Segment 2 is the distractor segment at the 0 -digit retention interval) cannot be done with the rules we were using for determining the number of 
potential perturbations applying to each segment at the various retention intervals. We used the rules employed by Lee and Estes (1981), Cunningham et al. (1984), and Healy et al. (1987): There are two reactivations (i.e., passive or automatic rehearsals, which provide opportunities for memory perturbations) of the hierarchy of codes during the presentation of the recall cue, of each interpolated digit, and of each letter occurring in a subsequent segment of letters (i.e., perturbations may occur for the letters in the first segment while the second segment is being presented). Because only the recall cue occurs after the second segment of letters with a 0 -digit retention in- terval, by these rules there are only two reactivations, or chances for perturbations to occur, in that case. Unless the primary-memory rehearsal parameter theta, the perturbation rate, is extremely high, it would be impossible to match the observed proportions of correct responses when Segment 2 is the distractor segment at the 0-digit retention interval with the fast presentation rate in the precue condition because the proportions are so low (.656, $.606, .628$, and .691 for Serial Positions 1, 2, 3, and 4, respectively, when noncompliance errors are eliminated). However, the perturbation model has no problems in predicting the level of performance when retention is tested
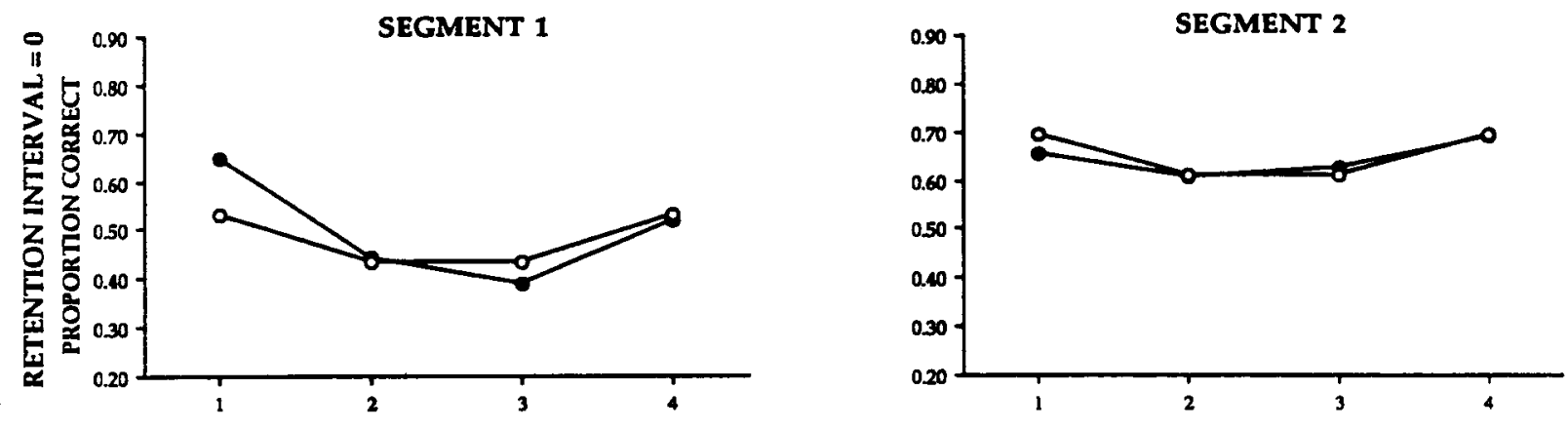

$\longrightarrow$ CORRECTED DISTRACTOR

$\longrightarrow$ MODEL, ALPHA $=.995$, THETA $=.04$
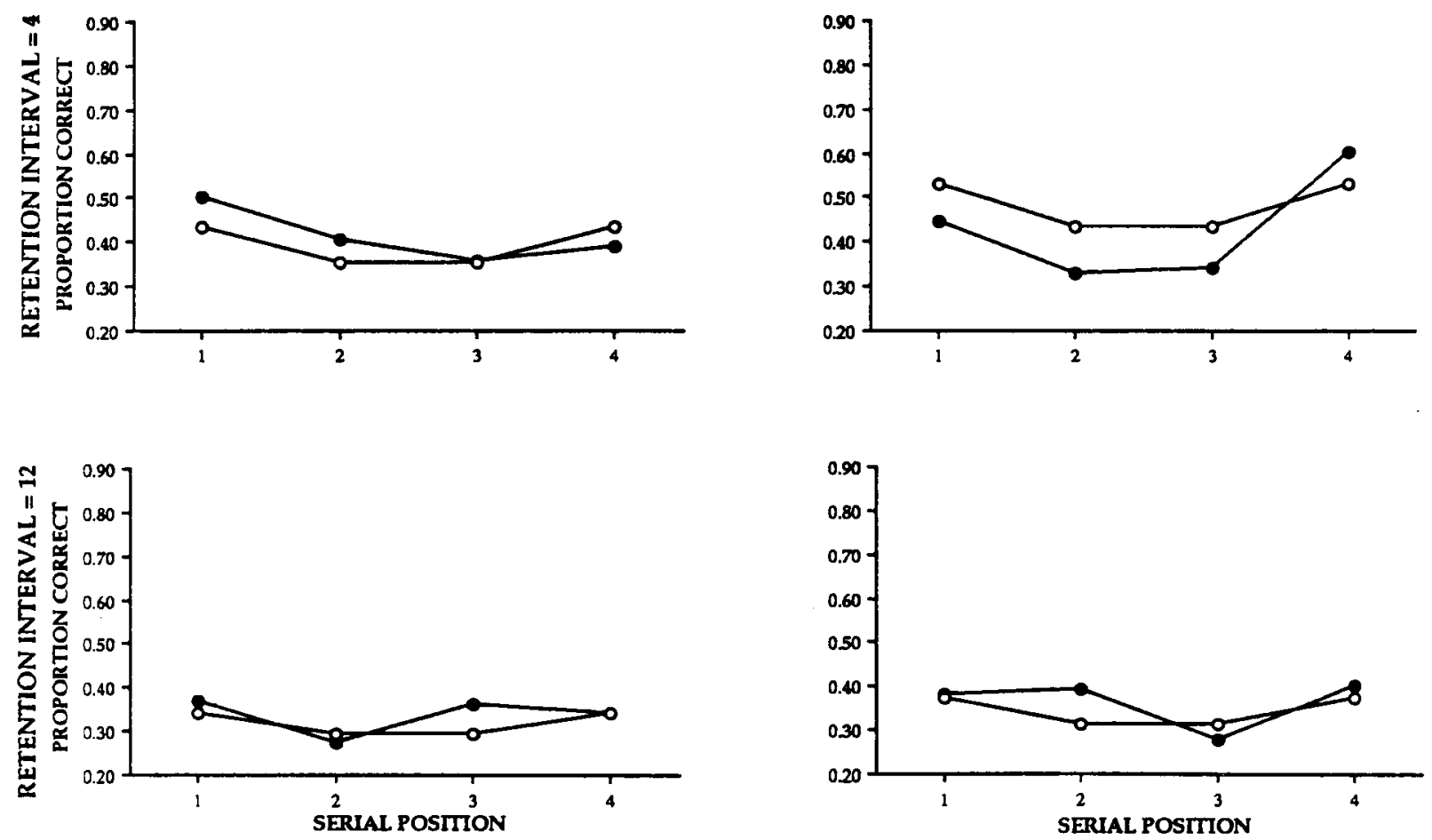

Figure 8. Obtained proportions of correct responses in Experiment 2 at the fast exposure rate of the precue condition, as a function of segment position, retention interval, and serial position for the corrected data of the distractor segment (filled circles) and the corresponding predictions of the modified perturbation model (unfilled circles) with $\theta=.04$ and $\alpha=.995$ when the recall cue is assumed to yield eight (instead of two) reactivations. 
immediately, if the rules are changed so that the recall cue always yields eight, instead of only two, reactivations or opportunities for memory perturbations. This increase in the reactivations for the recall cue is made to accommodate the disruption created when subjects process the recall cue, because it is at this point that the subjects must switch their attention from the cued target to the uncued distractor (which must be recalled first). In fact, with the rules changed in this way, we were able to account for the levels of performance on both segment positions at all three retention intervals in the critical test condition, which reduced elaborative encoding processes, when we kept the primary-memory rehearsal parameter theta constant at .04 (the value used in previous studies) and varied only the secondary-memory encoding parameter alpha. Under those conditions, we found the best fit with $\alpha=$ .995 , as is shown in Figure 8. The RMSD for this fit was .056. The predicted serial position functions do not correspond exactly in shape to the observed functions. The model predicts symmetrical bow-shaped functions for each segment and retention interval combination, but the observed functions were asymmetrical in many instances. Although the asymmetries were statistically significant (as has been noted in the Results section of Experiment 2), this discrepancy may not be serious, in light of the many inconsistencies between Experiments 1 and 2 in the shapes of the serial position functions shown in Figure 7. Furthermore, there are no major discrepancies between the observed and predicted data; and the correspondence between the model's predictions and the observed data (RMSD $=.056$ ) is at least as good as the correspondence between the observed data from Experiments 1 and 2 $(\mathrm{RMSD}=.067)$. The agreement between the predictions of the model and the observed data from Experiment 2 should not be expected to be better than the agreement between the observed data from Experiments 1 and 2. In other words, the discrepancies in the fit of the model are no greater than the discrepancies created by experimental noise obtained through replication. The discrepancies as reflected in the magnitude of the RMSD values are relatively modest in both cases.

What are the implications of finding a good fit to the critical test condition when theta is kept constant but both the number of reactivations associated with the recall cue and alpha are raised relative to the values used in previous studies? First, the need to increase the number of reactivations, or opportunities for perturbations, associated with the recall cue suggests that a substantial amount of forgetting occurs while the subjects are moving their attention from the target or cued segment to the distractor or noncued segment. Although we eliminated the element of surprise in the full report technique used in Experiment 2 , the subjects may, nevertheless, have experienced some disruption when they saw the recall cue because they first had to report the noncued, or distractor, segment rather than the cued, or target, segment. Simply by allowing the perturbation model to have some limited flexibility in the number of reactivations associated with a par- ticular episode, we were able to extend the model's ability to cope with task demands requiring a shift in attentional focus. It is interesting that in extending the perturbation model to long-term memory positional effects, Nairne $(1991,1992)$ also allowed for some flexibility in the number of reactivations associated with a particular episode.

Second, the need to increase the value of alpha, the secondary-memory encoding parameter, but not theta, the primary-memory rehearsal parameter, suggests that we were successful in isolating primary memory processes and reducing the influence of elaborative encoding. Indeed, the value of alpha yielding the best fit, .995 , was very close to the maximum value, 1.000 , which eliminates the secondary-memory component. The fact that we did not need to raise the value of theta (the perturbation rate or rate of forgetting from primary memory) suggests that there was no evidence in our study for very rapid forgetting from primary memory. The steep retention functions obtained by Muter (1980) and Sebrechts et al. (1989) then seem attributable to the elevated recall level in their studies at the 0 -sec retention interval, for which, unlike the other delay intervals, the subjects' recall expectancy was not reduced. The difference between our study and the studies by Muter and Sebrechts et al. in terms of the level of performance at the 0 -sec retention interval can thus be understood in terms of what happened during the recall cue. In our study, the subjects had to move their attention from one segment (the target) to another segment (the distractor) when the recall cue was presented. In contrast, no such movement of attention was required at the 0 - $\mathbf{s e c}$ retention interval in the studies by Muter and Sebrechts et al., although it was required at the longer retention intervals in those studies.

Applying the model to other test conditions. Now that we have established that the Estes perturbation model can account for the data from the critical test condition in Experiment 2, we can raise the question whether it can be extended to account for the data from the other test conditions in Experiment 2. Of most interest would be whether the same assumptions and parameter values that we adopted to fit the critical test condition could be applied when fitting the model to these other conditions. Toward this end, we made three additional comparisons of the model to data in Experiment 2: (1) We compared the corrected data from the distractor precue condition at the slow exposure rate (as opposed to the fast rate) with the model using the same assumptions concerning the number of reactivations (e.g., eight reactivations for the recall cue) and the same value of theta (.04), allowing only the value of alpha to differ from that used to fit the data from the critical test condition (i.e., the distractor precue condition at the fast exposure rate). We were able to achieve a good fit with alpha set equal to .960 , as reflected in the RMSD value of .065 . This finding suggests that changing the exposure rate has a large impact on secondary memory processes but no influence on primary memory processes. (2) We compared the corrected data from the target (as opposed to the distractor) precue 
condition at the fast exposure rate with the model employing the same value of theta (.04) used to fit the data from the critical test condition and the same value of alpha (.975) used in previous research (Healy et al., 1987) involving precuing. As in the earlier studies, we assumed that there were two reactivations for each stimulus letter and digit as well as for the recall cue (because it engendered no shift of attention for the target). To provide for the likely existence of output interference (see, e.g., Hadley, Healy, \& Murdock, 1992), we also made the straightforward assumption that there were similarly two reactivations for each response letter recalled or output by the subjects (i.e., thereby allowing for eight additional reactivations caused by the initial recall of the distractor segment). With these assumptions and parameter values, we obtained a good fit to the data, as reflected in an RMSD value of .067. (3) We compared the corrected data from the target (again, as opposed to the distractor) postcue (as opposed to precue) condition at the fast exposure rate with the model employing the same value of theta (.04) that was used to fit the data from the critical test condition and the same value of alpha (.985) that had been used in previous research (Healy et al., 1987) involving postcuing. We also made the same assumptions concerning reactivations as in the fit for the analogous precue condition (i.e., two for each stimulus and response character). Once again we obtained a good fit to the data, as reflected in an RMSD value of .059 . Hence, it is clear that the model has a broad range of applicability and can handle changes in presentation rate as well as changes due to expectancy and importance created by varying cuing condition and segment status.

We did not attempt to fit the model to the data of Experiment 1 , because it included fewer critical trials and did not include the crucial 0 -digit retention interval. Nevertheless, it should be noted that, as mentioned previously, there was a close correspondence (RMSD $=.067$ ) between the recall levels in the critical test conditions of the two experiments. The critical test condition in Experiment 1 involved the switch trials of the $75 \%$ precue condition at the fast exposure rate. When we compared performance on the same trials at the slow exposure rate with performance on the comparable trials in Experiment 2, we also found a close correspondence (RMSD $=.100$ ). Thus, it appears that the results of Experiment 1 are consistent with those from the analogous conditions of Experiment 2. Likewise, the data from Experiment 1 are consistent with those from the analogous conditions in the study by Healy et al. (1987, Experiment 2). Specifically, there is a close correspondence in recall performance for the standard precue condition both at the fast exposure rate (RMSD $=.095$ ) and at the slow rate (RMSD $=.067$ ) and for the standard postcue condition both at the fast rate $(\mathrm{RMSD}=.106)$ and at the slow rate $(\mathrm{RMSD}=.098)$. It therefore seems clear that the perturbation model could easily be applied with similar parameter values to the data from Experiment 1, as it was to the data from Experiment 2.

\section{Conclusions}

The goal of our study was to isolate primary memory processes by reducing secondary elaborative encoding within the context of the distractor paradigm commonly used to assess memory over short time intervals. The analysis of our results in terms of the Estes perturbation model suggests that we were quite successful in our attempt to reduce secondary memory processes. The perturbation model could account for performance in our critical experimental situation with only a minimal secondarymemory encoding component as long as the model provided for an unusual disruption in performance at the time of the recall cue presentation. Our successful reduction of elaborative encoding made it clear that despite the larger secondary-memory component in earlier studies with the standard distractor paradigm, the previous studies did not provide a distorted picture of primary memory processes. Indeed, the Estes perturbation model could provide an account of performance in our study with exactly the same perturbation rate (i.e., rate of forgetting from primary memory) suggested by earlier experiments. That is, we found no evidence for an accelerated rate of forgetting from primary memory when secondary memory processes were reduced in the distractor paradigm. The very rapid overall rate of forgetting observed in studies by Muter (1980) and Sebrechts et al. (1989) was found to be attributable to an elevated recall level at the 0 -sec retention interval in their studies. In the present study, we examined the retention of order information exclusively, whereas Muter and Sebrechts et al. examined the retention of item as well as order information. It is possible that the rate of forgetting from primary memory is more rapid for item information than for order information. However, the rapid forgetting found by Muter and Sebrechts et al. was most evident with their strict scoring method, which scored for order as well as item information, rather than with their lenient scoring method, which scored only for item information. Furthermore, Estes (1972) has persuasively argued that "the loss of order information is primary and the loss of item information is derivative" (p. 180). In any event, it is clear from the results of our study that very rapid forgetting from primary memory does not apply to the retention of order information.

The present research bolsters the important status of the perturbation model in our understanding of short-term memory processes. This model has long been held to provide crucial insights into the causes of forgetting from shortterm memory (see, e.g., Crowder, 1976, pp. 188-194) and has recently been shown to be useful for the understanding of long-term memory processes as well (see Nairne, 1991, 1992, who found reasonable qualitative fits of the perturbation model to results from studies examining long- 
term memory for sequential position following retention intervals of up to $24 \mathrm{~h}$ ). In the present study, the perturbation model was also successfully extended to tasks requiring shifts in attentional focus.

\section{REFERENCES}

ANDerson, N. S. (1960). Poststimulus cuing in immediate memory. Journal of Experimental Psychology, 60, 216-221.

BRown, J. (1954). The nature of set-to-learn and of intramaterial interference in immediate memory. Quarterly Journal of Experimental Psychology, 6, 141-148.

Brown, J. (1958). Some tests of the decay theory of immediate memory. Quarterly Journal of Experimental Psychology, 10, 12-21.

Craik, F. I. M., LockharT, R. S. (1972). Levels of processing: A framework for memory research. Journal of Verbal Learning \& Verbal Behavior, 11, 671-684.

Crowder, R. G. (1976). Principles of learning and memory. Hillsdale, NJ: Erlbaum.

Cunningham, T, F., Healy, A. F., \& Williams, D. M. (1984). Effects of repetition on short-term retention of order information. Journal of Experimental Psychology: Learning, Memory, \& Cognition, 10 , 575-597.

ESTES, W. K. (1972). An associative basis for coding and organization in memory. In A. Melton \& E. Martin (Eds.), Coding processes in human memory (pp. 161-190). New York: Halstead Press.

EsTes, W. K. (1983, August). Discussion of papers in the Symposium on Quantitative Models of Memory. Paper presented at the annual Mathematical Psychology Meeting, Boulder, CO.

Hadeey, J. A., Healy, A. F., \& Murdock, B. B. (1992). Output and retrieval interference in the missing-number task. Memory \& Cognition, 20, 69-82.

Healy, A. F., Cunningham, T. F., Gesi, A. T., Till, R. E., \& Bourne, L. E. (1991). Comparing short-term recall of item, temporal, and spatial information in children and adults. In W. E. Hockley \& S. Lewandowsky (Eds.), Relating theory and data: Essays on human memory in honor of Bennet B. Murdock (pp. 127-154). Hillsdale, NJ: Erlbaum.

Healy, A. F., Fendrich, D. W., Cunningham, T. F., \& Till, R. E. (1987). Effects of cuing on short-term retention of order information. Journal of Experimental Psychology: Learning, Memory, \& Cognition, 13, 413-425.

LEE, C. L., \& ESTES, W. K. (1977). Order and position in primary memory for letter strings. Journal of Verbal Learning \& Verbal Behavior 16, 395-418

LEE, C. L., \& EsTES, W. K. (1981). Item and order information in shortterm memory: Evidence for multilevel perturbation processes. Journal of Experimental Psychology: Human Learning \& Memory, 7 , 149-169.
Lofrus, G. R. (1985a). Consistency and confoundings: Reply to Slamecka. Journal of Experimental Psychology: Learning, Memory, \& Cognition, 11, 817-820.

LofTus, G. R. (1985b). Evaluating forgetting curves. Journal of Experimental Psychology: Leaming, Memory, \& Cognition, 11, $397-406$.

MURDOCK, B. B., JR. (1961). The retention of individual items. Journal of Experimental Psychology, 62, 618-625.

Muter, P. (1980). Very rapid forgetting. Memory \& Cognition, 8, 174-179.

NaIRNE, J. S. (1991). Positional uncertainty in long-term memory. Memory \& Cognition, 19, 332-340.

NAIRNE, J. S. (1992). The loss of positional certainty in long-term memory. Psychological Science, 3, 199-202.

NeELy, J. H. (1977). Semantic priming and retrieval from lexical memory: Roles of inhibitionless spreading activation and limited-capacity attention. Journal of Experimental Psychology: General, 106, 226-254.

Peterson, L. R., \& Peterson, M. J. (1959). Short-term retention of individual verbal items. Journal of Experimental Psychology, 58, 193-198.

Sebrechts, M. M., Marsh, R. L., \& Seamon, J. G. (1989). Secondary memory and very rapid forgetting. Memory \& Cognition, 17, 693-700.

SlameCKA, N. J. (1985). On comparing rates of forgetting: Comment on Loftus (1985). Journal of Experimental Psychology: Learning, Memory, \& Cognition, 11, 812-816.

SlameckA, N. J., \& McElreE, B. (1983). Normal forgetting of verbal lists as a function of their degree of learning. Journal of Experimental Psychology: Learning, Memory, \& Cognition, 9, 384-397.

SPERLING, G. (1960). The information available in brief visual presentations. Psychological Monographs, 74 (11, Whole No. 498).

Waugh, N. C., Norman, D. A. (1965). Primary memory. Psychological Review, 72, 89-104.

\section{NOTE}

1. Three additional subjects failed to reach the criterion of correctly recalling two target segments during the 12 practice trials. Two of these subjects were in the 500 -msec condition and 1 was in the 1,000 -msec condition. In addition, 4 subjects were eliminated during the experimental trials because they failed on several occasions to verbalize either the letters or the digits when they were presented on the display screen. Two of these subjects were in the 500 -msec condition, and 2 were in the 1,000-msec condition. Thus, of the 7 subjects eliminated and replaced, 4 were in the 500 -msec condition and 3 were in the 1,000 -msec condition.

(Manuscript received December 21, 1992; revision accepted for publication April 2, 1993.) 